\title{
Effect of Preheating on Microstructure and Tensile Properties of Friction Stir Welded AA7075 Aluminium Alloy Joints
}

\author{
R. Poongkundran ${ }^{1} *$, K. Senthilkumar ${ }^{2}$. \\ ${ }^{l}$ Assistant Professor, Department of Mechanical Engineering, Sri Rangapoopathi College of Engineering, Gingee, \\ Tamil Nadu, India. ${ }^{2}$ Professor, Department of Mechanical Engineering, Dhanalashmi Srinivasan College of \\ Engineering and Technology, Magabalipuram, Tamil Nadu, India.
}

\begin{abstract}
The high strength AA7075 aluminum alloy is commonly used in the aerospace components due to its exclusive mechanical properties like lightweight and high strength. This alloy cannot be welded by fusion welding techniques due to solidification cracking which severely degrade the mechanical properties of the joint. In contrast, through friction stir welding (FSW) process solidification relate defects can be eliminated. Anyhow, the strength of friction stir welded joint is influenced by process parameters and tool parameters. These parameters govern the heat input, metal flow, microstructure evolution and mechanical properties of the weld. In normal welding condition, (without preheating) heat is generated by friction force which is produced between tool and workpiece. In this paper an added heat input through preheating the metal before weld. This preheating temperature effects on microstructure, microhardness and tensile properties of the joints were investigated. From this study the following conclusions are derived. Sufficient heat input should be given to obtain defect free and quality joint. The results showed that, preheating the base metal to $100{ }^{\circ} \mathrm{C}$ prior to welding improved the tensile strength and joint efficiency compared to the joints made without preheating.
\end{abstract}

Key words: Aluminum alloy, Preheating, Friction stir welding, Tensile strength, Microstructure

\footnotetext{
*Author for correspondence: pkundranme@gmail.com
} 


\section{INTRODUCTION}

Friction Stir Welding (FSW) is a solid state welding process which was developed by TWI in the United Kingdom two and half decades before. In this technique, a nonconsumable rotating tool is plunged at the interface of base metals. This thermo-mechanical action between the tool and base metal produce frictional heat, as the result a base metal around the tool is locally plasticized. This plasticized metal at the front of the tool is extruded and forged at the back end of the tool when tool moved forward, thus the weld joint is produced [1-3].

In commercial point of view, productivity of friction stir welded component is a challenging task. It means that increasing welding speed beyond optimal value is not possible. As the welding speed increases the heat input reduces as well as the corresponding heating area around the tool also reduces which leads to poor quality weld joint [4]. In addition higher welding speed also leads to tool failure, for this reason many researcher have been replaced costly tools [9]. Few authors have improved welding speed of friction stir welding by preheating the base metal with external heat source [5-9].

In normal friction stir weld preheating of base metal is achieved by increasing the dwell time period in the plunging stage. Increasing dwell time period does not offer significant temperature improvement in weld [5]. For preheating external heating can be used, it is recognized through analytical model that external heat can enhance quality of the weld and also increase the welding speed [6]. Preheating of base metal of the weld improved the strength and Vickers hardness of the weld joint [7]. External heating provide at the bottom of the weld plate also improved the strength of the weld [8]. Different methods of preheating are employed, Yaduwanshi, et al. used plasma for preheating in friction stir welding to weld aluminum alloy[12], Lotfi et al. designed a preheating setup and optimized its process parameters [13], and Sun et al. applied gas welding torch for preheating in friction stir spot welding of carbon steel weld [9]. Form these literatures it can be suggested that preheating with gas weld torch is the simple and effective approach among these preheating techniques. This simple gas weld torch heating was implemented in this research.

Preheating can improve the welding speed but it reduces the frictional stress of base metal which results in less friction heat generation [5]. It also reduces shear stress and stirring action, reducing of these values beyond certain limit will lead to defected joint [1]. The preheating can support the loss of heat generation. So it is required to study the effect of preheating temperature on mechanical strength of weld. Never the less, the characteristic changes in FSW with preheating temperature not yet studied. Maximum possible preheating temperature for better strength of weld has not been reported elsewhere. Hence, an attempt has been made to investigate the relations between preheating temperature and mechanical characteristics of friction stir welded AA7075-T651 aluminum alloy joint. The study focuses on improvement of tensile strength, finding of optimal preheating temperature and analysis the changes in microstructure under preheated condition.

\section{EXPERIMENTAL WORK}

The rolled aluminum alloy AA7075-T651 plate of thickness $6.35 \mathrm{~mm}$ was used as parent metal for this investigation. Chemical composition and mechanical properties of this base metal are listed in Table 1 and Table 2 respectively. The plate was reduced into rectangles of dimension $100 \mathrm{~mm}$ length and $75 \mathrm{~mm}$ width. These machined plates were welded in normal to the rolling direction using computer numerical controlled FSW machine (22 kW, $4000 \mathrm{rpm}, 6$ ton). A taper 
pin threaded profiled tool made of super high speed steel was used to fabricate all the weld joints. The tool geometry of the tool is given in the Fig. 1.

Table 1 Chemical composition of AA7075-T651 aluminum

\begin{tabular}{llllllll}
\multicolumn{1}{l}{ alloy } \\
\hline $\mathrm{Mg}$ & $\mathrm{Cu}$ & $\mathrm{Cr}$ & $\mathrm{Fe}$ & $\mathrm{Ti}$ & $\mathrm{Si}$ & $\mathrm{Mn}$ & $\mathrm{Al}$ \\
\hline 2.5 & 1.4 & 0.19 & 0.14 & 0.07 & 0.04 & 0.02 & $\begin{array}{l}\text { Remainin } \\
\mathrm{g}\end{array}$ \\
\hline $\begin{array}{l}\text { Table } 2 \\
\text { alloy }\end{array}$ & Mechanical properties & of AA7075-T651 aluminum \\
\hline $\begin{array}{l}\text { Tensile } \\
\text { strength } \\
(\mathrm{MPa})\end{array}$ & $\begin{array}{l}\text { Yield } \\
\text { strength } \\
\text { (MPa) }\end{array}$ & $\begin{array}{l}\text { Elongation } \\
(\%)\end{array}$ & Hardness $\left(\mathrm{HV}_{0.05}\right)$ \\
\hline 599 & 479 & 7.5 & & \\
\hline
\end{tabular}

\begin{tabular}{|l|}
\hline Tool Dimensions: \\
Length of the pin $(\mathrm{L})$ \\
$-5.7 \mathrm{~mm}$ \\
Major diameter of the pin \\
$(\mathrm{dM})-6 \mathrm{~mm}$ \\
Minor diameter of the pin \\
$(\mathrm{dm})-5 \mathrm{~mm}$ \\
Shoulder diameter $(\mathrm{D})$ \\
$-18 \mathrm{~mm}$ Pitch of thread \\
- $1 \mathrm{~mm}$
\end{tabular}

The selected process parameters for this research yielded defect free joint. The used parameters to fabricate the normal weld are tool rotational speed of $900 \mathrm{rpm}$, welding speed of $25 \mathrm{~mm} / \mathrm{min}$ and tool title angle of $1.5^{\circ}$. To study the effect of preheating temperature the above process parameters were kept constant and preheating temperature alone was varied as $100{ }^{\circ} \mathrm{C}, 150{ }^{\circ} \mathrm{C}, 200{ }^{\circ} \mathrm{C}$, and $250{ }^{\circ} \mathrm{C}$. With these temperatures five preheated weld joints were fabricated. These fabricated weld joints are shown in Fig. 2. Here, preheating of base metal was achieved by gas torch. Tool followed preheating torch to allow the base metal to heat. During the welding, peak temperature of each joint was measured near to the stir zone. These temperatures are given in table 3. The joint fabricated without preheating is referred as PRERT joint. Other joints are referred as follows: PRE10 (preheated to $100{ }^{\circ} \mathrm{C}$ ), PRE15 (preheated to $150{ }^{\circ} \mathrm{C}$ ), PRE20 (preheated to $200{ }^{\circ} \mathrm{C}$ ), PRE25 (preheated to $250{ }^{\circ} \mathrm{C}$ ). These welded joints were cut and machined to obtain unnothched and notched tensile specimens with dimension as specified in ASTM E8 M-04 guidelines [14]. The dimensions of the tensile specimen are shown in Fig. 3. The tensile test was carried out in $100 \mathrm{kN}$, servo controlled universal testing machine (Model: UNITEK 94100, Make: FIE - BLUESTAR, INDIA). The metallographic samples were prepared and etched with Keller's reagent to expose the microstructure in different zones of weld nugget. The microstructure of the weld samples were examined using optical microscope. Scanning electron microscope (SEM) was used to view the features at fractured surfaces of broken tensile specimens. The hardness values were measured along the weld centerline by using a Vickers microhardness testing machine with a load of $0.05 \mathrm{~kg}$ and a dwell time of $15 \mathrm{~s}$ at $1 \mathrm{~mm}$ step. 
Table 3 Measured peak temperature of each joint

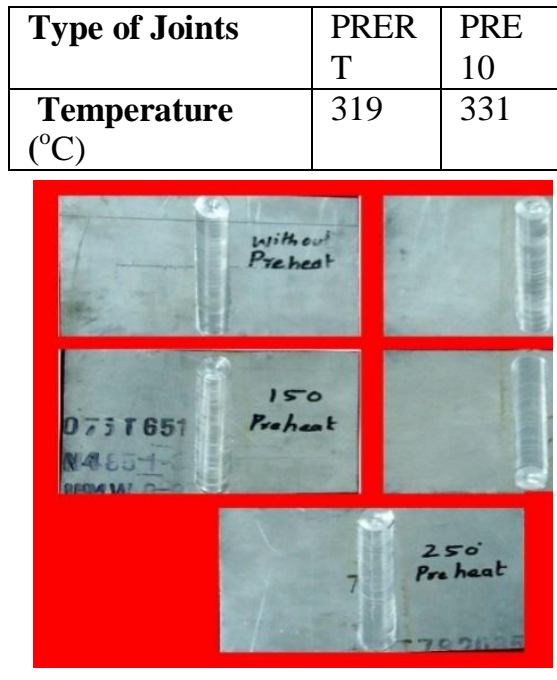

Fig. 2 Photograph of fabricated joints.

\begin{tabular}{|l|l|l|l|}
\hline PRE & PRE & PRE \\
15 & 20 & 25 \\
\hline 367 & 398 & 411 \\
\hline
\end{tabular}

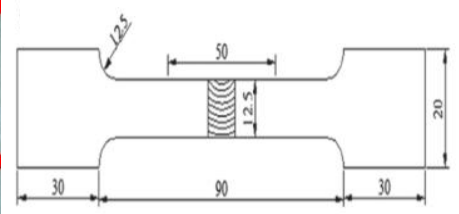

(a) Unnotchied specimen

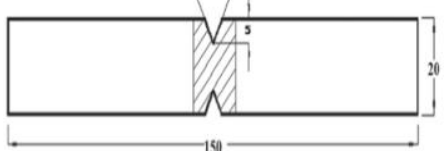

(b) Notched specimen

Fig. 3 Dimensions of tensile specimen

\section{RESULTS}

\section{Macrostructure Analysis}

Asymmetric weld regions were observed in all weld joints. Friction stir weld is commonly divided into four different regions they are Stir Zone (SZ), Thermomechanical Affected Zone (TMAZ), Heat Affected Zone (HAZ) and Base Material (BM) [2]. Fig. 4 shows top surface appearance and corresponding cross-sectional macrograph of all joints. Semicircular traces were observed on top of welds these traces became smoother with increasing preheating temperature [15]. Here increase in heat input makes the surface smoother. It is found that SZ width of preheated weld joints is larger than that of PRERT joint. The stir zone width increased up to $150{ }^{\circ} \mathrm{C}$ (PRE15) preheating temperature and it decreased drastically thereafter. The maximum stir zone width is measured as $8.1 \mathrm{~mm}$ in PRE15 joint. The width of retreating side thermo-mechanical affected zone (RS-TMAZ) is greater than the width at advancing side thermo-mechanical affected zone (AS-TMAZ) in all the joints [10]. From this macro level assessment, all joints were defect free except PRE25 joint, in this joint lack of fill defect was found on top it is also visible in cross-sectional macrographs [4]. 


\begin{tabular}{|c|c|c|c|}
\hline Joint type & Top surface of the joint & Cross section of the joint & Defect and zone width \\
\hline PRERT & & & $\begin{array}{l}\text { No defects } \\
\text { SZ : } 6.8 \mathrm{~mm} \\
\text { AS-TMAZ: } 1.7 \mathrm{~mm} \\
\text { RS-TMAZ: } 2.2 \mathrm{~mm}\end{array}$ \\
\hline PRE10 & & & $\begin{array}{l}\text { No defects } \\
\text { SZ width: } 7.5 \mathrm{~mm} \\
\text { AS-TMAZ: } 2.3 \mathrm{~mm} \\
\text { RS-TMAZ: } 3.0 \mathrm{~mm}\end{array}$ \\
\hline PRE15 & & & $\begin{array}{l}\text { No defects } \\
\text { SZ width: } 8.1 \mathrm{~mm} \\
\text { AS-TMAZ: } 2.5 \mathrm{~mm} \\
\text { RS-TMAZ: } 3.5 \mathrm{~mm}\end{array}$ \\
\hline PRE20 & an & & $\begin{array}{l}\text { No defects } \\
\text { SZ width: } 6.9 \mathrm{~mm} \\
\text { AS-TMAZ: } 2.5 \mathrm{~mm} \\
\text { RS-TMAZ: } 3.7 \mathrm{~mm}\end{array}$ \\
\hline PRE25 & $<$ & & $\begin{array}{l}\text { Tunnel defects } \\
\text { SZ width: } 6.8 \mathrm{~mm} \\
\text { AS-TMAZ: } 2.4 \mathrm{~mm} \\
\text { RS-TMAZ: } 4.0 \mathrm{~mm}\end{array}$ \\
\hline
\end{tabular}

Fig. 4 Surface appearance and corresponding cross-sectional macrograph of all joints

\section{MICROSTRUCTURE ANALYSIS}

The base metal microstructure is shown in Fig. 5, it consists of course and elongated grains with $\mathrm{MgZn}_{2}$ precipitates present in grain boundaries $[13,16]$. The microstructures of Stir zone (SZ), thermo-mechanical affected zone (TMAZ) and heat affected zone (HAZ) of all welds were analyzed under optical microscope. These optical microscope images are presented in Fig. 6. Grain structures were also studied in top (shoulder affected stir zone), middle and bottom (pin affected stir zone) of the SZ region, which is shown in Fig. 7. Examining these three stir zone regions in PRERT joint, low aspect ratio coarse grains is observed in the shoulder affected region, these grains are coarser than that of in the middle SZ region [11]. The finer grains are observed in the pin affect region than that in middle stir zone region it is due to sufficient stirring action caused by tool [25]. Similar type of grain pattern at SZ is observed in all preheated weld joints. Stir zone is dynamically recrystallized into equiaxied grains through plastic deformation due to high temperature and high pressure in all joints [11].

The average grain size values of SZ in PRERT, PRE10, PRE15, PRE20 and PRE25 are $6 \mu \mathrm{m}, 8 \mu \mathrm{m}, 8 \mu \mathrm{m}, 10 \mu \mathrm{m}$ and $10 \mu \mathrm{m}$ respectively. TMAZ is not dynamically recrystallized but deformed due to minimum strain. These zone grain sizes are linearly proportion to preheat temperature. HAZ is not affected by strain but it experienced the thermal cycle during welding due to this reason the grains present in HAZ region became coarsened [13]. Two different pin-hole defects are shown in 


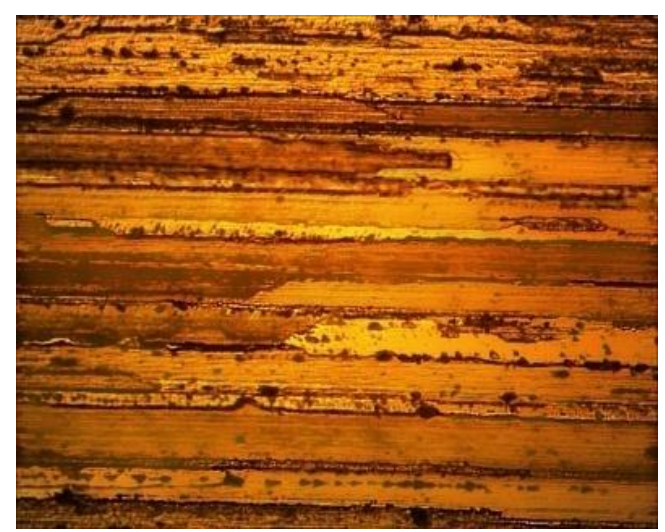

Figure.5 Base metal microstructure

Fig. 8. The defect showed Figure $8 \mathrm{a}$ was found at $(800 \mathrm{rpm})$ low spindle speed. This defect is presented for comparison study purpose alone it is taken from this preliminary work. Figure $8 \mathrm{~b}$ shows the pin-hole defect found in PRE20 weld joint. Comparing these two images, the pinhole defect in PRE20 has partially melted metal, where as in the other defect partially melted metal has not found.

\section{TENSILE PROPERTIES}

The average tensile test results of different weld conditions are given in table 4 . The tensile strength of the friction stir welded joints is inferior to that of the base metal [17]. PRE10 and PRE15 weld joints are observed higher ultimate tensile strength (UTS) than PRERT weld. However PRE10 weld joint produced maximum ultimate tensile strength of $385 \mathrm{MPa}$ and its joint efficiency was $64 \%$. The improved joint efficiency of this joint is $11 \%$ due to preheating of base metal. The PRE20 weld joint produced

The average grain size values of SZ in PRERT, PRE10, PRE15, PRE20 and PRE25 are $6 \mu \mathrm{m}, 8 \mu \mathrm{m}, 8 \mu \mathrm{m}, 10 \mu \mathrm{m}$ and $10 \mu \mathrm{m}$ respectively. TMAZ is not dynamically recrystallized but deformed due to minimum strain. These zone grain sizes are linearly proportion to preheat temperature. HAZ is not affected by strain but it experienced the thermal cycle during welding due to this reason the grains present in HAZ region became coarsened [13]. Two different pin-hole defects are shown in Fig. 8. The defect showed Figure 8a was found at $(800 \mathrm{rpm})$ low spindle speed. This defect is presented for comparison study purpose alone it is taken from this preliminary work. Figure $8 \mathrm{~b}$ shows the pin-hole defect found in PRE20 weld joint. Comparing these two images, the pinhole defect in PRE20 has partially melted metal, where as in the other defect partially melted metal has not found. 
Effect on Aluminium Alloy Joints Properties

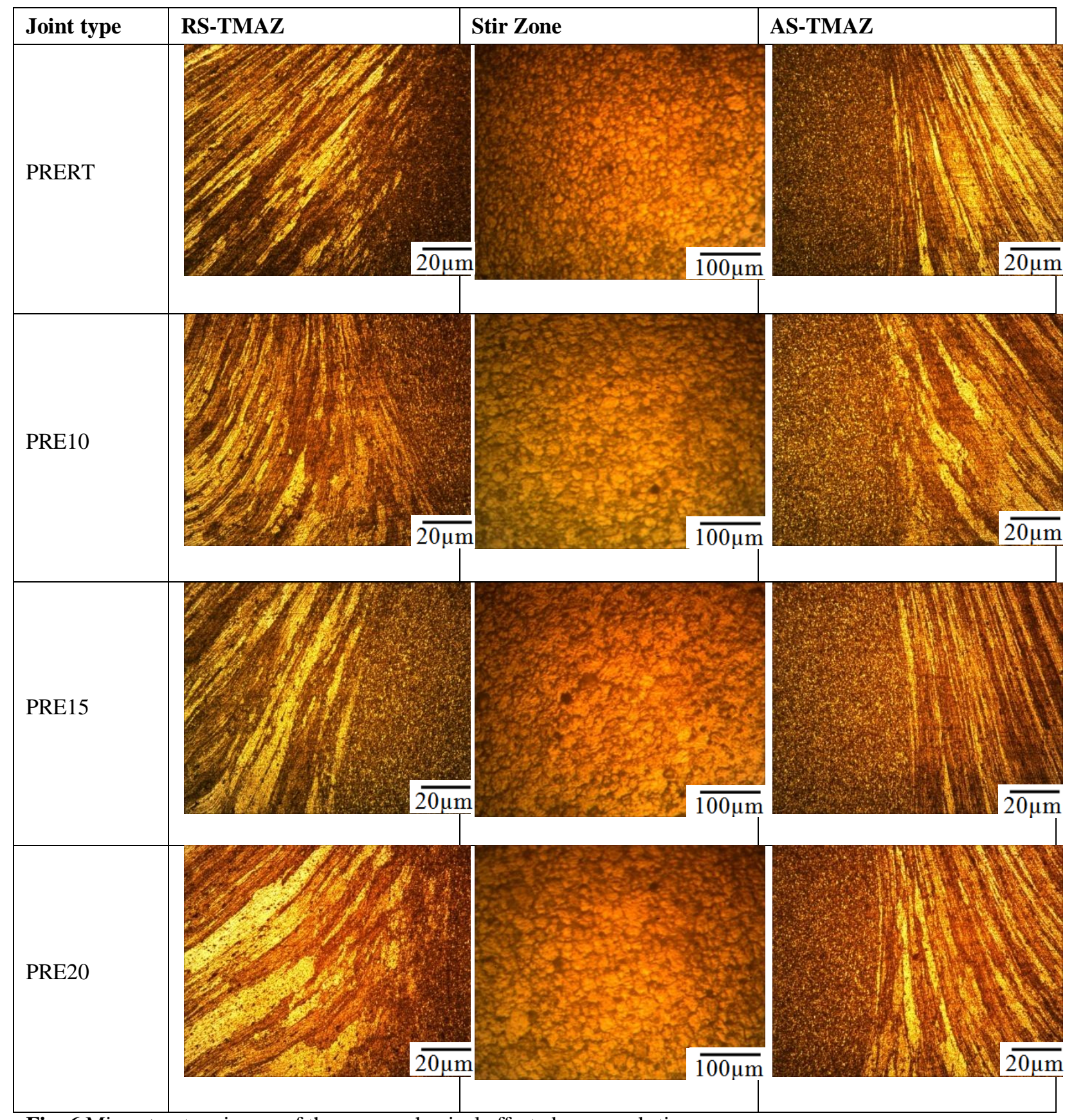

Fig. 6 Microstructure image of thermo-mechanical affected zone and stir zones

\section{TENSILE PROPERTIES}

The average tensile test results of different weld conditions are given in table 4 . The tensile strength of the friction stir welded joints is inferior to that of the base metal [17]. PRE10 and PRE15 weld joints are observed higher ultimate tensile strength (UTS) than PRERT weld. However PRE10 weld joint produced maximum ultimate tensile strength of $385 \mathrm{MPa}$ and its joint efficiency was $64 \%$. The improved joint efficiency of this joint is $11 \%$ due to preheating of base metal. The PRE20 weld joint produced lower ultimate tensile strength compared to all other joints because of presence of defect in it. PRE25 weld joint is not tested because of

Braz. Arch. Biol. Technol. v.59: e16161056 Jan/Dec 2016 Spec Iss 2 
presence of defect. The percentage of elongation increased initially up to $150{ }^{\circ} \mathrm{C}$ (PRE15) than it decreased. The maximum percentage of elongation of $5.31 \%$ is measured in PRE15 weld, but its UTS value is lower than the PRE10 weld joint. This higher percentage of elongation of PRE15 weld joint is also evidenced in the load-displacement curve (Fig. 9) preheating temperature improved the ductility of this joint. The fracture location and corresponding fracture surface microstructure of all the tensile specimens are shown in Fig. 10. PRE10 and PRE15 joints were fractured at AS-HAZ $[17,21]$. PRERT and PRE20 weld joints fractured AS TMAZ [18]. Even they failed in different locations, ductile mode of failure is observed in facture location microstructures. Notched tensile specimens fracture location and corresponding fracture surface microstructure of all joints is shown in Fig. 11. The value of notch strength ratio (NSR) is found to be around one in all specimens it means that the joints are notch ductile [18].

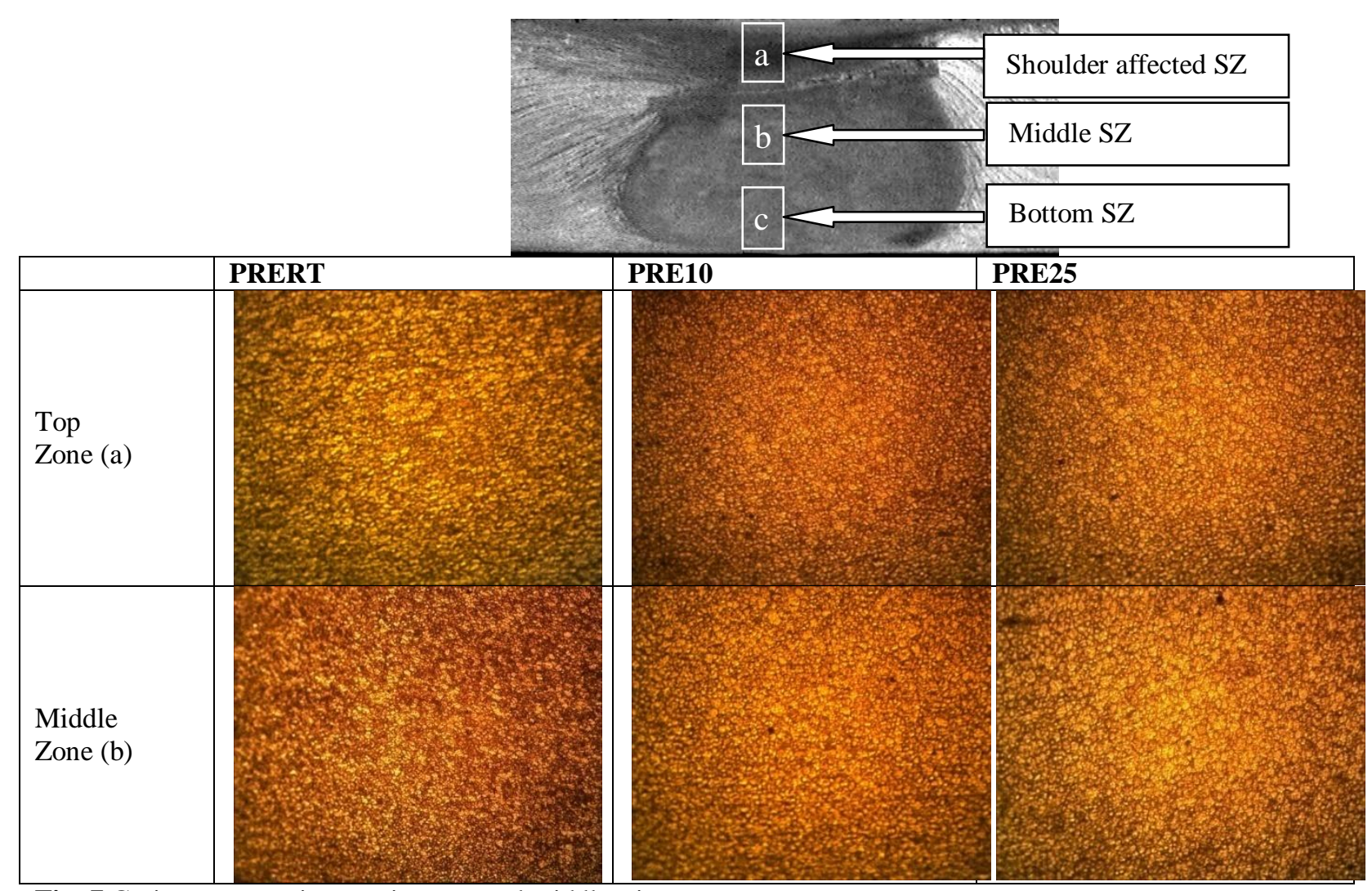

Fig. 7 Grain structures in top stir zone and middle stir zone 
Effect on Aluminium Alloy Joints Properties

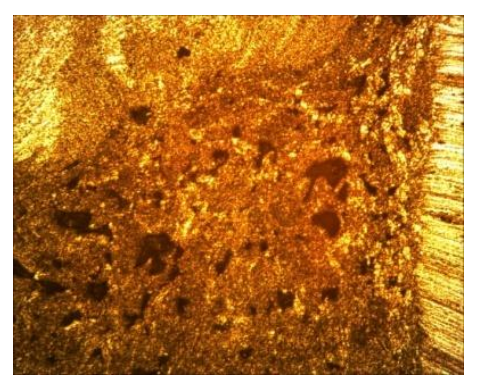

Fig. 8 (a) Pin hole defect formed in low spindle speed

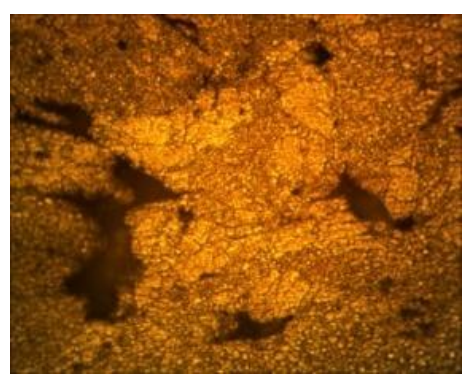

Fig. 8 (b) Pin hole defect in PRE20 weld joint

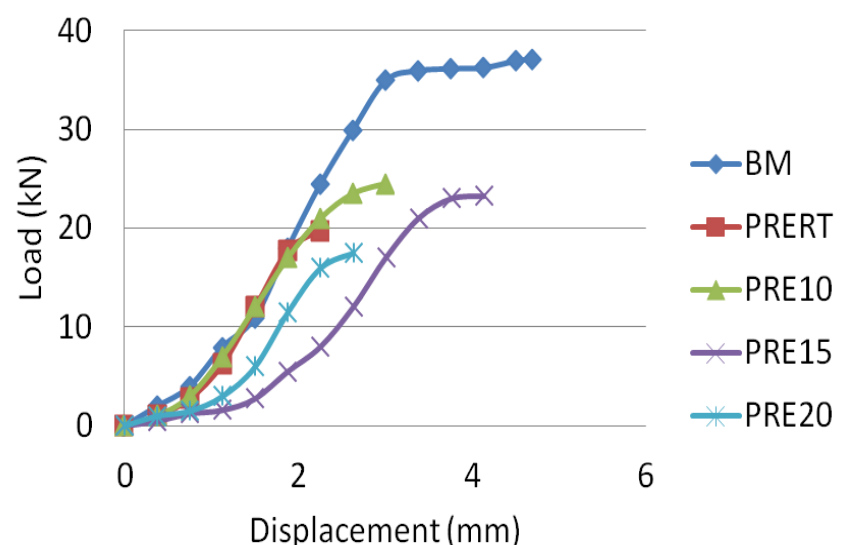

Fig.9 Load Vs displacement curves in tensile test

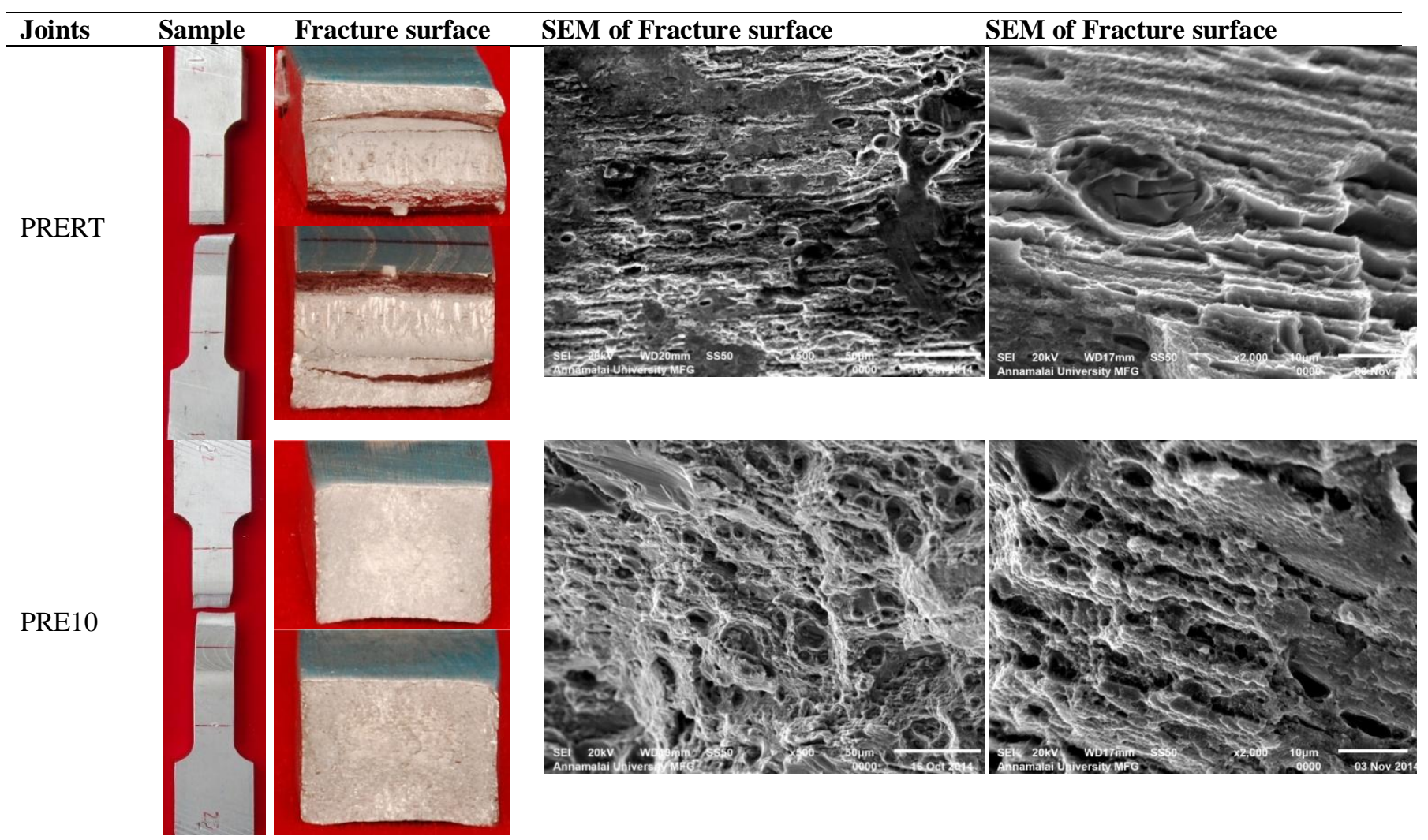

Braz. Arch. Biol. Technol. v.59: e16161056 Jan/Dec 2016 Spec Iss 2 


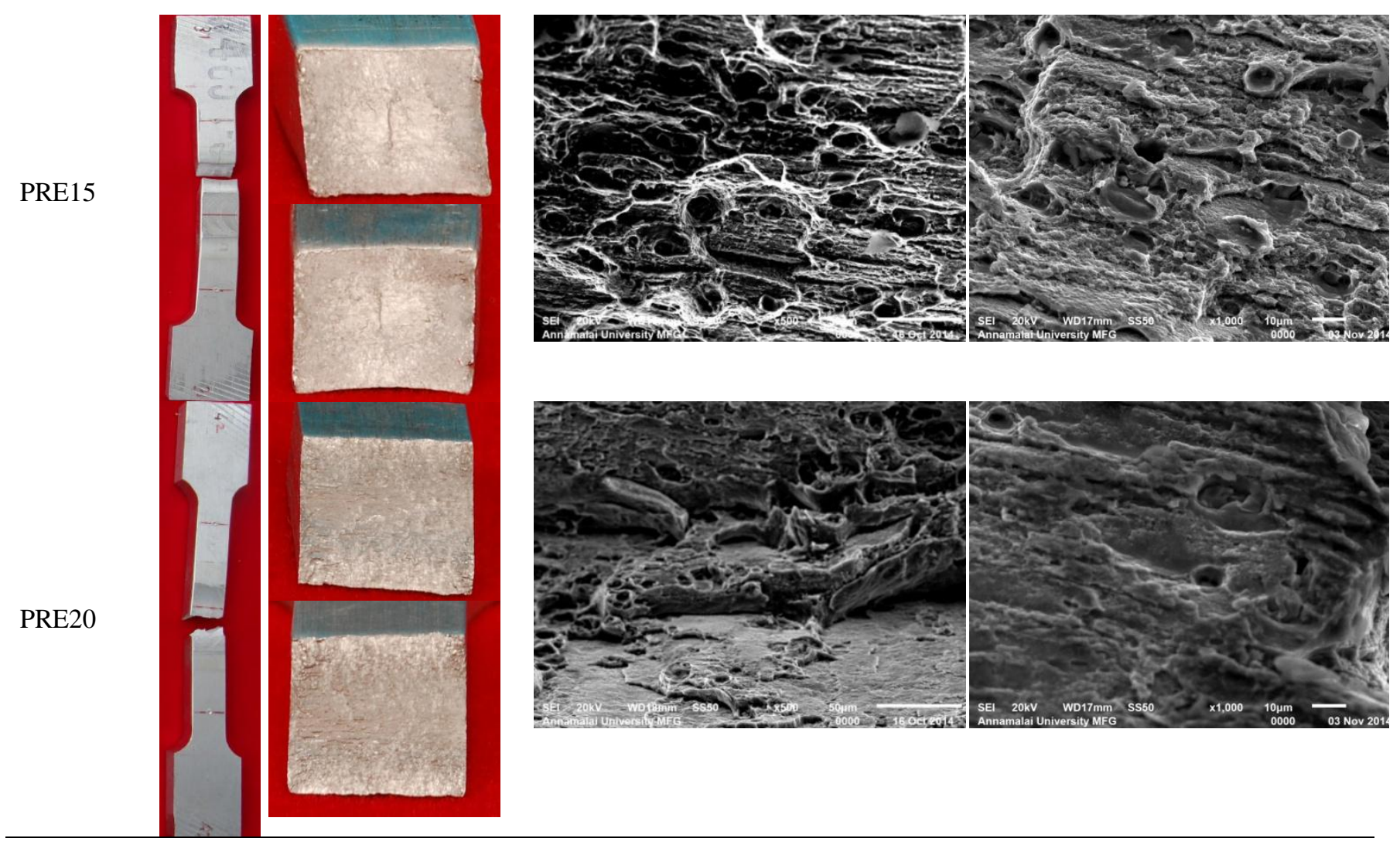

Fig. 10 Fracture location and corresponding Fracture location microstructures of unnotched tensile specimens

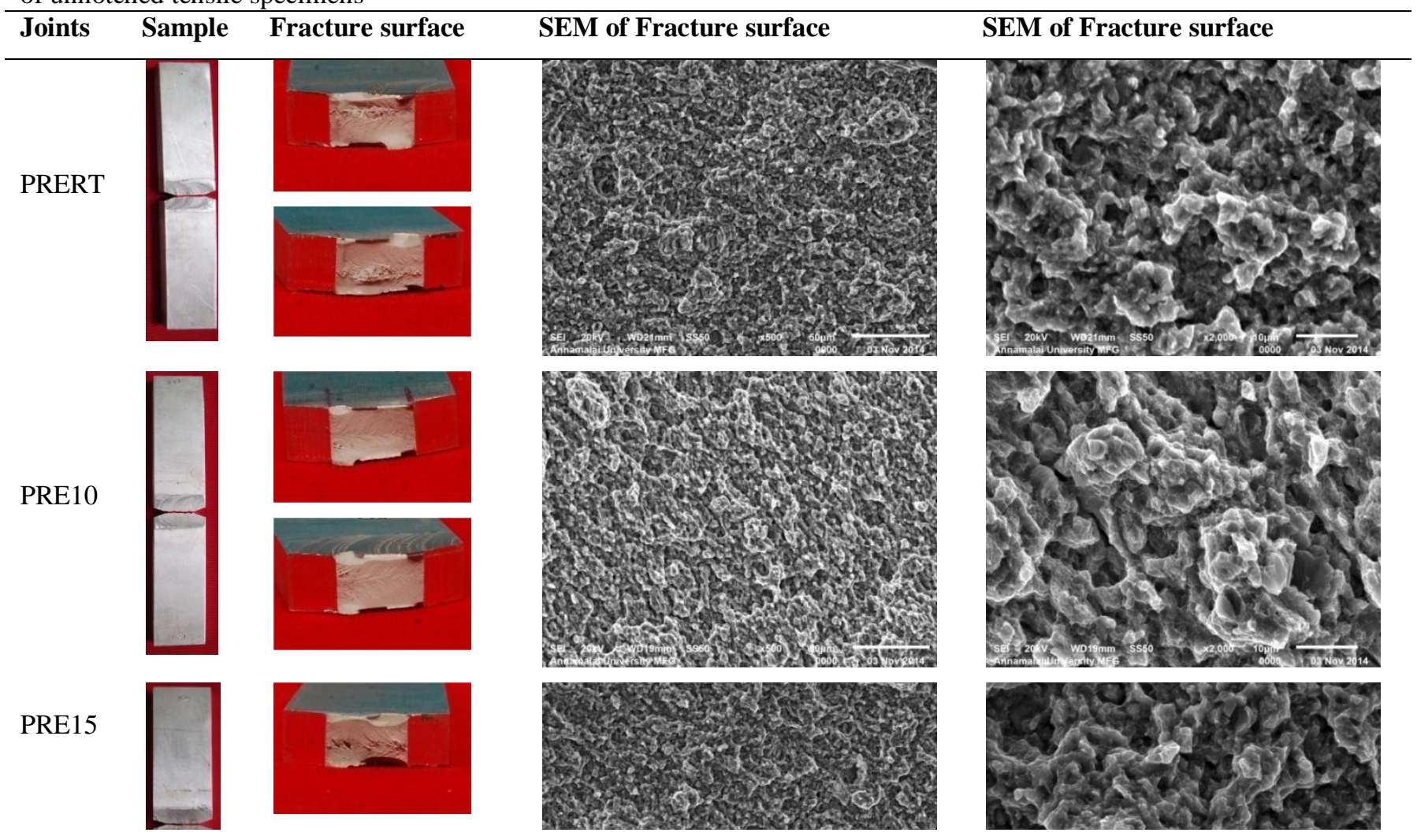


Effect on Aluminium Alloy Joints Properties

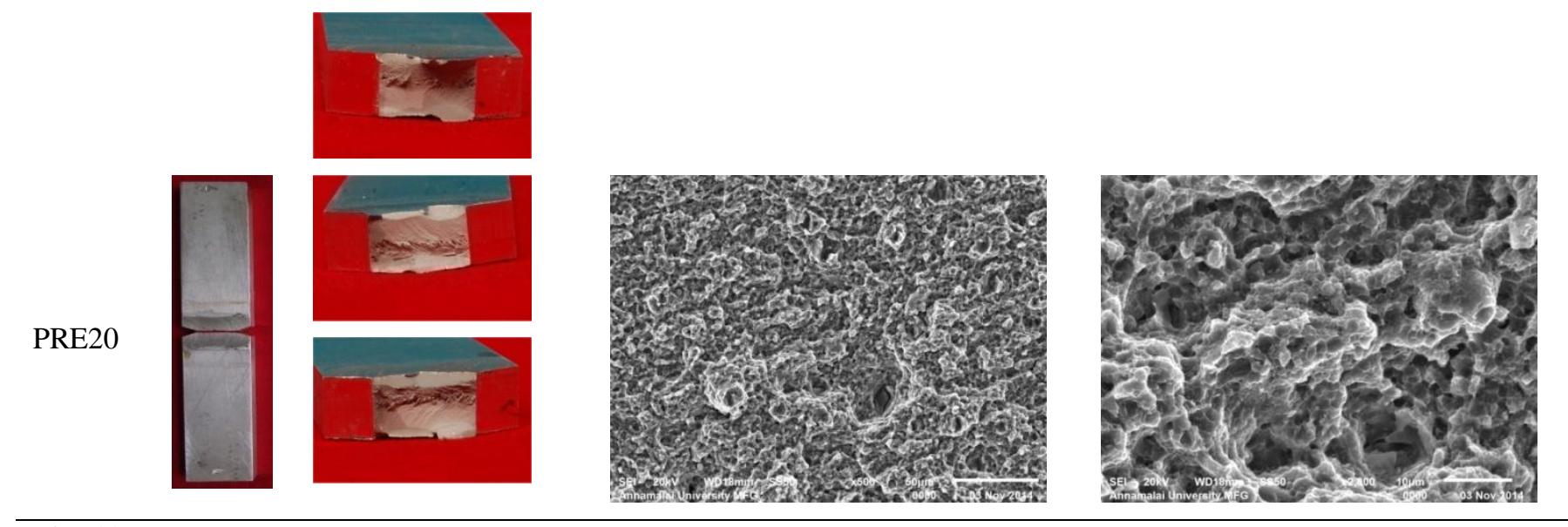

Fig. 11 Fracture location and corresponding Fracture location microstructures of notched tensile specimens

\section{MICROHARDNESS}

The microhardness profiles of all joints are measured at the center line of the cross section of the weld, this profile plot is represented in Fig. 12. Hardness profile is observed as ' $W$ ' in shape [17]. Intermediate hardness value is measured at stir zone. TMAZ is revealed lower hardness value while higher hardness is observed in base metal [17]. In HAZ, the hardness is gradually increasing from TMAZ value to the base metal value. From hardness profile diagram, it is revealed that the width of RS-TMAZ is greater than the width of AS-TMAZ for all weld joints, but ASTMAZ hardness value is considerably higher than RS-TMAZ [19, 20]. The average hardness valve at the stir zone of PRERT, PRE10, PRE15, and PRE20 are 138.4, 136.18, 131.47, and 129.46 HV respectively. In PRE15, and PRE20 weld joints, preheating of the base metal decreases the hardness value in all weld zones as well as increases the weld zone width of these joints. In PRE10 weld joint, stir zone width only increases and the hardness of this zone is slightly lower than the normal weld joint (PRERT) but hardness in heat affected zone is slightly higher than normal weld joint.

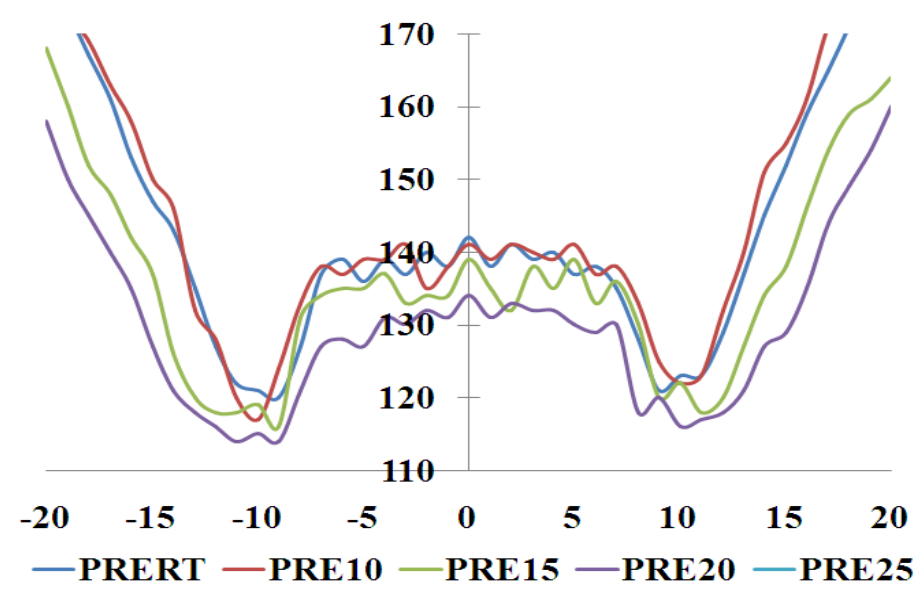

Fig. 12 Hardness profile plot 


\section{DISCUSSION}

The presence of pinhole defect and lack of fill defect in PRE20 and PRE25 welds respectively reduce the process temperature which reduces the stir zone width in these joints [4]. The reduction in heat is because of the following; one decrease the coefficient of friction due to local melting of metal around the pin and the other is absorbed by the latent heat of melting of the metal [23]. But in the widths of thermomechanical zone and heat affected zone of these joints are increased as well as hardness reduced due to over ageing temperature and slow cool [26]. In the joint PRE20 (Fig 8b) had the pinhole defect and surrounded by partially melted metal, this is due to excess heat input to this joint. Here, the increasing in heat input did not continue in development of stir zone size due to slipping of tool. Since excess heat reduces flow stress and reduced coefficient of friction cases tool to Slip at thermomechanical zone [24]. Due to this no recrystallization take place near to pinhole defect. This microstructure image is the evidence results

In normal friction stir welding, the increase heat input to the weld joint leads to reduce the stir zone region [22]. But, in contrast to the above, the stir zone size is increased even in addition of heat input it is one of the significant effect by preheating. Rising in preheating temperature reduces the shear strength and widens the heated area, this combined effect facilitated in enlarging the stir zone width of PRE10 and PRE15 welds.

Slightly low aspect ratio fine grains are found in PRERT weld joint microstructure (Fig.7) at the shoulder affected region. It is result of low heat input observed and tool wake over in the region [11]. This low heat input is the reason for rough semicircular traces on the top of weld in this joint. In PRE10 and PRE15 weld joints low aspect ratio fine grains are disappeared and also weld top surfaces became smoother. Stir zone grain size is increased with preheating temperature it was due to rise in temperature of the plate, which led to slow cooling. Because of slow cooling welding grain undergo nucleation resulting static grain growth in stir zone of the weld [9].

PRERT was fractured at TMAZ in advancing side. In normal weld joint (PRERT) the weak area is present at TMAZ interface in advancing side [17] the same result was obtained in this research also. But PRE10 and PRE15 joints fractured at the at HAZ region, it shows that preheating of base metal makes alter the week area from TMAZ to HAZ in these joints it is also a evidence for better integration between stir zone and TMAZ. This is another finding which support for improved strength in PRE10 and PRE15 weld joints.

Microhardness of the joint depends on thermal cycle in which the weld joint undergoes. In friction stir welding different zone will have different peak temperature and consecutive cooling time this leads to different grain size at different weld regions, which decide the hardness value of the joint. According to the Hall-Petch equation, hardness and grain size are inversely proportional. Due to this phenomenon, hardness has decreased with the increase in preheat temperature in preheated weld joints [27]. Peak ageing temperature of precipitation hardened AA7075 aluminum alloy is $140{ }^{\circ} \mathrm{C}$ [13]. Addition to this for AA7075 aluminum alloy maximum hardness is achieved at $150^{\circ} \mathrm{C}$ in short duration, above is over ageing [26]. Whereas in PRE15, joint was heated above peak aging temperature, which is over aged so formation of soft zone is higher than PRE10. It is evident from hardness test results of PRE15 weld had lower hardness than PRE10 joint also higher weld zone width than PRE10 joint. These make PRE15 weld joint in lower tensile strength. 
The temperature was measured in the HAZ during welding of PRE10 is $133{ }^{\circ} \mathrm{C}$ is near to peak aging temperature, during this temperature coarsening process of the second phase particles will take place in the HAZ [28]. It evidenced in microhardness plot, hardness value at HAZ of PRE10 weld joint is higher than that of PRERT weld joint. Improved hardness, better integration between stir zone and TMAZ and stir zone development are supporting PRE10 weld joint for maximum ultimate tensile strength.

\section{CONCLUSION}

In this investigation an attempt was made to analyze the effect of preheating temperature on the tensile properties and microstructure characteristic of AA7075 aluminum alloy. Form this investigation the following conclusions are derived i)Preheating of base metal above peak ageing temperature will not provide better joint efficiency.

ii) Preheating of weld improves the stir zone size and TMAZ size which is not possible in the normal FSW procedure

iii) Preheating provides another source of heat input apart from the spindle speed, so strength of stir zone is improved. Stirring effect is also improved through preheating.

iv) Of the four levels of preheating temperature applied, the joint made with a preheating temperature of $100{ }^{\circ} \mathrm{C}$ showed higher tensile properties than the other preheated joints and improvement in joint efficiency is $11 \%$.

\section{ACKNOWLEDGEMENT}

We are grateful to Mr. V. Balasubramanian, Professor, Center for Materials Joining and Research (CEMAJOR), Department of Manufacturing Engineering, Annamalai University for his kind support and guidance to carry out this research work.

\section{REFERENCES}

1. Balasubramanian, "Relationship between base metal properties and friction stir welding process parameters," Materials Science and Engineering A, vol.480,pp. 397-403, 2008 .

2. $\mathrm{N}$ Rajamanickam, and $\mathrm{V}$ balusamy, "Effects of process parameters on mechanical properties of friction stir welds using design of experiments," Indian journal of engineering \& materials sciences, vol.15, pp. 293-299, 2008.

3. Omar Hatamleh, Rajiv S. Mishra, and Ovidio Oliveras "Peening effects on mechanical properties in friction stir welded AA 2195 at elevated and cryogenic temperatures," Materials and Design, vol. 30,pp. 3165-3173, 2009.

4. Daniela Lohwasser, and Zhan Chen, "Friction stir welding from basics to applications," CRC Press, 2010.

5. R. Keivani, B. Bagheri, F. Sharifi, M. Ketabchi, and M. Abbasi, "Effects of pin angle and preheating on temperature distribution during friction stir welding operation," Trans. Nonferrous Met. Soc. China, vol. 23, pp. 2708-2713, 2013.

6. Masoud Jabbari, "Effect of the Preheating Temperature on Process Time in Friction Stir Welding of Al 6061-T6," Journal of Engineering, vol. 2013, pp.5, 2013.

7. Omid Ali Zargar, "The Preheating Influence on Welded Joint Mechanical Properties Prepared by Friction Stir Welding Aluminum Alloy H20-H20," Middle-East Journal of Scientific Research, vol.15 (10), pp. 1415-1419, 2013.

8. Kandasamy, M Manzoor Hussain, and S. Rajesham, Experimental investigation on the influence of external heating on the mechanical and metallurgical properties in 
friction stir welding of 7075 alloys, International conference on design and advances in mechanical engineering, pp 266-271, 2011.

9. Y.F. Sun, J.M. Shen, Y. Morisada, and H. Fujii, "Spot friction stir welding of low carbon steel plates preheated by high frequency induction," Materials and Design, vol. 54, pp. 450-457, 2014.

10. S.D. Ji, Y.Y. Jin, Y.M. Yue, S.S. Gao, Y.X. Huang, and L. Wang, "Effect of temperature on material transfer behavior at different stages of friction stir welded 7075-T6 aluminum alloy," Journal of material science and technology, pp. 1-6, 2003.

11. Mao Yuqing, Ke Liming, Liu Fencheng, Liu Qiang, Huang Chunping, and Xing $\mathrm{Li}$, "Effect of tool pin eccentricity on microstructure and mechanical properties in friction stir welded 7075 aluminum alloy thick plate," Materials and Design, 2014.

12. D.K. Yaduwanshi, S. Bag, and S. Pal, "Effect of Preheating in Hybrid Friction Stir Welding of Aluminum Alloy," Journal of Materials Engineering and Performance, vol.29, 2014.

13. H. Lotfi, and S. Nourouzi, "Predictions of the optimized friction stir welding process parameters for joining AA7075-T6 aluminum alloy using preheating system," International Journal of Advance Manufacturing Technology, vol.28, 2014.

14. ASTM E8 M-04. Standard test method for tension testing of metallic materials. ASTM International, 2006.

15. Sung-Ook YOON, Myoung-Soo KANG, Hyun-Bin NAM, Yong-Jai KWON, Sung-Tae HONG, Jin-Chun KIM, Kwang-Hak LEE, Chang-Yong LIM, and Jong-Dock SEO, "Friction stir butt welding of A5052-O aluminum alloy plates," Transactions of Nonferrous Metals Society of China, vol. 22, pp 619-623. , 2012.

16. H. Khalid Rafi, G.D. Janaki Ram, G. Phanikumar, and K. Prasad Rao, "Microstructure and tensile properties of friction welded aluminum alloy AA7075-T6," Materials and Design, vol. 31, pp. 2375-2380, 2010.

17. Christian B. Fuller, Murray W. Mahoney, Mike Calabrese, and Leanna Micona, "Evolution of microstructure and mechanical properties in naturally aged 7050 and $7075 \mathrm{Al}$ friction stir welds," Materials Science and Engineering A, vol. 527, pp. 2233-2240, 2010.

18. P. Sivaraj, D. Kanagarajan, and V. Balasubramanian, "Effect of post weld heat treatment on tensile properties and microstructure characteristics of friction stir welded armour grade AA7075-T651 aluminium alloy," Defence Technology, vol. 10, pp. 1-8, 2014.

19. Rebecca Brown, Wei Tang, and A.P. Reynolds, "Multi-pass friction stir welding in alloy 7050-T7451: Effects on weld response variables and on weld properties," Materials Science and Engineering A, vol. 513-514, pp. 115-12, 2009.

20. K.Ramanjaneyulu, G. Madhusudhan Reddy, A. Venugopal Rao, and R. Markandeya, "Structure-Property Correlation of AA2014 Friction Stir Welds: Role of Tool Pin Profile," Journal of Materials Engineering and Performance, vol. 22, pp. 2224-2240, 2013.

21. Emanuela Cerri, and Paola Leo, "Influence of high temperature thermal treatment on grain stability and mechanical properties of medium strength aluminium alloy friction stir welds," Journal of Materials Processing Technology, vol. 213, pp. 75-83, 2013. 22. Colegrove P.A., Shercliff H.R. and Zettler R., "Model for predicting heat generation and temperature in friction stir welding from the material properties," Science and Technology of Welding and Joining, vol. 12, pp. 284-297, 2007.

23. S. Rajakumar, C. Muralidharan, and V. Balasubramanian, "Influence of friction stir welding process and tool parameters on strength properties of AA7075-T6 aluminium alloy joints," Materials and Design, vol. 32, pp. 535-54, 2011.

24. R. Nandan, G.G. Roy, T.J. Lienert, and T. Debroy, "Three-dimensional heat and material flow during friction stir welding of mild steel," Acta Materialia, vol. 55, pp. 883895, 2007.

25. R.K.R. Singh, Chaitanya Sharma, D.K. Dwivedi, N.K. Mehta, and P. Kumar, "The microstructure and mechanical properties of friction stir welded $\mathrm{Al}-\mathrm{Zn}-\mathrm{Mg}$ alloy in as welded and heat treated conditions," Materials and Design, vol. 32, pp. 682-687, 2011. 26. Shwe Wut Hmon Aye, Kay Thi Lwin, and Waing Waing Kay Khine Oo, "The Effect of Ageing Treatment of Aluminum Alloys for Fuselage Structure-Light Aircraft," World Academy of Science and Engineering and Technology, vol. 46, 2008. 
Effect on Aluminium Alloy Joints Properties

27. Wang Xunhong, and Wang Kuaishe, "Microstructure and properties of friction stir butt-welded AZ31 magnesium alloy," Materials Science and Engineering A, vol. 431, pp. 114-117, 2006.

28. Rui-dong Fu, Zeng-qiang Sun, Rui-cheng Sun, Ying Li, Hui-jie Liu, and Lei Liu, "Improvement of weld temperature distribution and mechanical properties of 7050 aluminum alloy butt joints by submerged friction stir welding," Materials and Design, vol. 32, pp. 4825-4831, 2011.

Received: February 03, 2016; Accepted: July 14, 2016 